\title{
Social Risk Factor
}

National Cancer Institute

\section{Source}

National Cancer Institute. Social Risk Factor. NCI Thesaurus. Code C102711.

Social factors such as personal behavior, lifestyle, or environment belong ing to the subject which are known to increase the likelihood of infection and disease. 